\title{
Coulisses
}

Revue de théâtre

19 | Hiver 1999

Varia

\section{Rencontre avec un auteur : Claude Louis-Combet}

Organisée par le Centre Jacques-Petit en partenariat avec le TUFC dans le cadre du programme « Le temps des écrivains à l'université et dans les grandes écoles » promu par La Maison des Écrivains

\section{Lucile Garbagnati}

\section{(2penEdition}

\section{Journals}

Édition électronique

URL : https://journals.openedition.org/coulisses/5629

DOI : $10.4000 /$ coulisses.5629

ISSN : 2546-9460

\section{Éditeur}

Presses universitaires de Franche-Comté

\section{Édition imprimée}

Date de publication : 1 janvier 1999

Pagination : 49

ISBN : 2-913322-09-3

ISSN : $1150-594 X$

Référence électronique

Lucile Garbagnati, «Rencontre avec un auteur : Claude Louis-Combet », Coulisses [En ligne], 19| Hiver 1999, mis en ligne le 18 octobre 2019, consulté le 12 janvier 2022. URL : http://

journals.openedition.org/coulisses/5629; DOI : https://doi.org/10.4000/coulisses.5629

Ce document a été généré automatiquement le 12 janvier 2022.

Coulisses 


\section{Rencontre avec un auteur : Claude Louis-Combet}

Organisée par le Centre Jacques-Petit en partenariat avec le TUFC dans le cadre du programme « Le temps des écrivains à l'université et dans les grandes écoles » promu par La Maison des Écrivains

\section{Lucile Garbagnati}

\section{La Maison des Écrivains}

1 «Lieu de débat et de réflexion sur la création littéraire, lieu de rencontre et de documentation, la Maison des Écrivains favorise la transmission des arts du langage dont les écrivains sont porteurs, ainsi qu'un dialogue vivant et créatif avec le texte. Elle souhaite ainsi, avec le soutien de la Fondation du Crédit Mutuel pour la lecture, donner la possibilité aux enseignants-chercheurs, aux chargés de mission Action culturelle d'une Université ou d'un CROUS, et aux étudiants eux-mêmes, d'inviter et de rencontrer des écrivains de langue française et/ou étrangère et de travailler avec eux. $»^{1}$

\section{Le Centre de recherches Jacques-Petit}

Il est le centre de recherches de littérature française de l'Université de Franche-Comté. Devenu au fil du temps référence internationale de la recherche claudélienne, il a diversifié ses auteurs, sa méthodologie et ses problématiques. C'est ainsi qu'il accueille les manuscrits de Claude Louis-Combet, et qu'il souhaite partager avec le public la jubilation d'une œuvre de tout premier plan. 


\section{L'essentiel : une œuvre et son auteur : Claude Louis- Combet}

3 Une œuvre au genre difficile à classer au confluent du roman, du récit, de l'autobiographie, de la poésie : un seul thème l'amour, celui de la femme et de la langue, relevant d'une même origine, sujets d'une exaltation fervente. L'œuvre de Claude Louis-Combet, c'est l'élan de l'enfant, de l'adolescent, de l'adulte vers 'inconnu, vers la femme, vers la vie. C'est l'amour, la passion de la langue, de la femme, de l'homme. Pour tous ceux qui aiment: grand-père, grand-mère, pères, mères, époux, épouses, frères, sœurs, amants, amantes, les livres de Claude Louis-Combet portent la parole drue, exigeante, créatrice d'une langue vraie, érotique et amoureuse.

Certaines de ses œuvres ont été adaptées pour le théâtre, d'autres sont en cours d'adaptation.

La langue qui a goûté à toutes les horreurs et à toutes les délices se glisse dans la phrase et lui apporte rythme, tension et consistance. Le texte naît de l'épiphanie des viscères. Tout le corps de l'homme s'y trouve engagé. Mais c'est la langue qui est l'organe majeur de la création verbale. Elle a le goût du désir et le goût de l'infini et c'est un seul et même goût. ${ }^{2}$

\section{L'œuvre de Claude Louis-Combet}

Elle se compose d'une trentaine d'ouvrages classés en : « Fiction », «Essais », « Poésie », publiés entre 1970 et 1998 chez différents éditeurs, José Corti, Flammarion, La Différence, Lettres Vives, Albin Michel, Deyrolle, Cadex, Brandes.

Dernier ouvrage paru: Le recours au mythe, José Corti, novembre 1998.

7 Que choisir pour une découverte ? Choix éminemment subjectif parmi les « fictions »: Marinus et Marina (Flammarion, 1979), Le Roman de Mélusine (Albin Michel, 1986), Le Bœuf-Nabu ou les métamorphoses du Roi des rois, (Lettres Vives, 1992), Blesse, ronce noire (José Corti, 1995).

\section{Avant-programme de l'après-midi}

Faculté des Lettres (salle à préciser)

- Présentation de la rencontre par France Marchal et Marie-Pierre Gaviano, enseignanteschercheuses au Centre Jacques-Petit.

- Claude Louis-Combet par lui-même : son parcours, son œuvre. Échange avec la salle.

- Présentation d'un ouvrage de l'auteur par un étudiant. Échange avec l'auteur et avec la salle.

- Lecture par le TUFC. Échange avec l'auteur et avec la salle.

- Pot amical. 


\section{NOTES}

1. Extrait du Dossier de présentation de la Maison des Écrivains, 53 rue Verneuil, 75007 Paris, tél 01495468 80, 0142842087.

2. In Le Don de Langue, p. 44, éditions Lettres Vives, 1992. 